\title{
"Ao Persistirem os Sintomas, o Médico Deverá Ser Consultado". \\ Isto é Regulação?
}

\author{
ÁLVAROCÉSAR NASCIMENTO"
}

JANE DUTRA SAYD $*$

\section{RESUMO}

O tripé formado pela indústria farmacêutica, agências de publicidade e empresas de comunicação tem implementado intensa estratégia de marketing para elevar o consumo de medicamentos pela população. Esta realidade impõe um desafio: na utilização de medicamentos, até onde prevalece a exigência terapêutica voltada para o controle de enfermidades e começa a pressão mercadológica a estimular o seu consumo? Por outro lado, a exploração do valor simbólico do medicamento pela grande mídia passa a representar poderoso instrumento de indução de hábitos para elevar seu consumo. Em novembro de 2000, a Agência Nacional de Vigilância Sanitária publica a Resolução de Diretoria Colegiada 102, tentando impor limites ao setor. Este estudo analisa cem propagandas de medicamentos veiculadas entre os meses de outubro de 2002 e julho de 2003, compara suas mensagens com os limites da nova legislação e conclui que todas elas agridem um ou mais artigos da Resolução. Para além de um maior esforço fiscalizador, este trabalho discute o próprio modelo regulatório adotado, que não tem conseguido alcançar o objetivo a que se propõe.

Palavras-chave: Medicamento; vigilância sanitária; ética na propaganda; regulação; mídia.

Recebido em: 28/03/2005.

Aprovado em: 29/08/2005. 


\section{Introdução}

O tripé formado pela indústria farmacêutica, agências de publicidade e empresas de comunicação tem implementado uma intensa estratégia de marketing com vistas a elevar o consumo de medicamentos no Brasil. Já os constantes avanços tecnológicos têm alterado o padrão de enfrentamento terapêutico de doenças, e seu impacto no setor saúde tem aprofundado as conseqüências do fenômeno da medicalização e da lógica de que os medicamentos devem ser considerados mercadorias como as demais.

Esta realidade impõe a resolução de pelo menos dois desafios: 1) na utilização de medicamentos, até onde prevalece a exigência terapêutica estritamente voltada para o controle de enfermidades e começa a pressão mercadológica a estimular o seu consumo? 2. Até que ponto a exploração do valor simbólico do medicamento pela grande mídia passa a representar um poderoso instrumento de indução de hábitos para elevar seu consumo?

Primeira causa de intoxicação humana no Brasil desde 1995 (quando se excluem as tentativas de suicídio, passa a ser a segunda causa), todo medicamento possui significativo potencial de risco e as reações adversas multiplicam-se com o uso incorreto e irracional. Idosos, crianças e portadores de doenças crônicas formam um enorme contingente exposto à propaganda de medicamentos, sem que ela traga nenhum tipo de advertência quanto ao uso de determinadas substâncias nocivas a esses grupos.

A magnitude do problema tem feito, há pelo menos 20 anos, com que o Estado busque regular essa propaganda, através de leis, decretos e códigos que, com o passar do tempo, foram sendo constantemente desrespeitados pela indústria, pelas agências de publicidade e pelas empresas de comunicação. Em 30 de novembro de 2000, a Agência Nacional de Vigilância Sanitária (ANVISA) publica a Resolução de Diretoria Colegiada (RDC) 102, a mais recente legislação que tenta novamente impor limites ao setor.

\section{A Propaganda como Combustível da Medicalização}

Para se ter idéia da magnitude das questões envolvendo a propaganda de medicamentos, ela é indicada como um dos principais problemas relacionados ao mercado farmacêutico no Brasil pelo Voto em Separado (apresentado por 6 dos 18 deputados da Comissão) ao Relatório Final da Comissão Parlamentar 
de Inquérito (CPI) de Medicamentos da Câmara dos Deputados, que teve seus trabalhos finalizados em maio de 2000 (BRASIL, Congresso, Câmara, 2000).

Entre os graves problemas identificados pela CPI, estão: "o superfaturamento no preço das matérias-primas adquiridas nas matrizes das indústrias no exterior" (p. 58); "a cartelização do setor" (p. 12) no Brasil; "o abuso nos preços praticados" (p. 54); "o estímulo à empurroterapia" (p. 77) e a comercialização de produtos sem comprovação científica de seu real impacto na saúde ${ }^{1}$ (p. 56). (BRASIL, Congresso, Câmara, 2000).

Os deputados indicaram, ainda, como questões a serem enfrentadas pelo poder público: o estímulo à automedicação (p. 77); a lentidão na implantação dos genéricos (p. 27); a falta de investimentos no parque industrial farmoquímico público (p.16); a inexistência de uma política voltada para a pesquisa científica (p. 20) e o sucateamento do Sistema Nacional de Vigilância Sanitária (p. 31). (BRASIL, Congresso, Câmara, 2000).

Junto com esses problemas, a CPI apontou a inexistência de regulação da propaganda de medicamentos (BRASIL, Congresso, Câmara, 2000) como uma questão que deveria ser urgentemente tratada.

A discussão sobre uma presença mais interventora do poder público na área da propaganda de medicamentos vem sendo travada há mais de 20 anos (pelo menos desde a Lei $n^{\circ}$ 6.360, de 23 de setembro de 1976) e há várias instituições representativas de consumidores, profissionais de saúde, parlamentares e sociedades científicas (como a Sociedade Brasileira de Vigilância de Medicamentos - Sobravime) que defendem a utilização de medicamentos "de acordo com as necessidades da população e não determinada pela interferência dos mecanismos de promoção destes produtos realizada pelos seus fabricantes" (HERXHEIMER e COLLIER, 1990, p. 307; HEINECK et al., 1996, p. 197).

Na tentativa de elevar o padrão de consumo dos medicamentos, o tripé indústria / agências de publicidade / empresas de mídia tem lançado mão de diferentes formas de propaganda, dirigidas tanto ao público "leigo" como aos profissionais de saúde.

Para se ter uma idéia da magnitude dos interesses que cercam o setor da publicidade de medicamentos, segundo a Federação Brasileira da Indústria Farmacêutica, no ano de 2002 o mercado farmacêutico no Brasil movimentou um total aproximado de $\mathrm{R} \$ 14,9$ bilhões (FEBRAFARMA, 2003). Dados da 
última CPI dos Medicamentos demonstram que cerca de 30\% dos recursos do setor são gastos com publicidade a cada ano, o que demonstra que o setor da propaganda de medicamentos movimentou cerca de $\mathrm{R}$ \$,5 bilhões só em 2002 no Brasil (BRASIL. Congresso. Senado, 2000). Parte importante desses recursos foi gasta em verbas para veiculação de publicidade em rádios, redes de televisão, mídia impressa, produção de anúncios pelas agências de publicidade, cachês pagos a artistas, atletas e personalidades que se transformam em garotos e garotas-propaganda da indústria de medicamentos.

Conforme já demonstrado por vários autores, a propaganda consegue alterar o padrão da prescrição dos médicos, sendo considerada, ainda, uma das principais fontes de sua atualização terapêutica. Os prescritores "confrontamse, constantemente, em sua prática de trabalho, com incertezas sobre o diagnóstico, sobre os possíveis prognósticos de um quadro diagnosticado, bem como sobre os benefícios e os riscos de sua intervenção em cada paciente ou grupo de pacientes" (TEMPORÃO, 1986, p. 21). Por outro lado,

\begin{abstract}
"as práticas de marketing dos medicamentos foram se diversificando no decorrer dos anos. Atualmente, há uma variedade de formas promocionais. As mais simples são a distribuição de brindes, amostras grátis e veiculação de vários tipos de informação, como panfletos, guias de produtos, propagandas em revistas médicas e em meios de comunicação de massa, como televisão, rádios e outdoors. Entre as mais complexas estão o financiamento da educação médica continuada, de pesquisas para desenvolvimento de protocolos de uso para fármacos de interesse e a promoção de eventos ditos científicos financiados pela indústria farmacêutica” (TEMPORÃO, 1986, p. 105).
\end{abstract}

"Apesar de os médicos acharem que sua decisão no ato prescritivo é baseada na literatura científica, as fontes de informações comerciais se mostram, ainda que subjetivamente, de importante influência" (PEPE, 1995, p. 7). Para viabilizar o processo de convencimento, a indústria utiliza diversas técnicas, como a promoção de congressos, visitas de propagandistas aos consultórios, anúncios em revistas técnicas e até o financiamento de viagens para que o profissional conheça parques industriais farmacêuticos dentro e fora do País (TEMPORÃO, 1986).

Diretamente junto à população consumidora de produtos farmacêuticos, a propaganda é utilizada como mais um instrumento de reforço da, já existente, cultura da medicalização. Esse fator atua fortemente associado à ideologia de 
consumo - disseminada na sociedade - como caminho mais rápido de se alcançar saúde, bem-estar e, em última instância, a felicidade.

"Os medicamentos, produzidos em escala industrial de acordo com especificações técnicas e legais, alcançaram papel central na terapêutica e, simbolicamente, ultrapassaram as fronteiras do que se pode entender como mero recurso terapêutico" (NASCIMENTO, 2002, p. 4).

Estudos farmacológicos demonstram que se medicalizam cada vez mais fenômenos ligados à vida cotidiana e não à prevalência de alguma doença, como o estímulo à utilização de preparados polivitamínicos como substitutos de uma dieta adequada, que não é valorizada como fonte privilegiada de nutrientes. Ou a prescrição de hipnosedantes para tratar insônia e ansiedade, em casos associados ao estresse gerado pelos hábitos de vida da sociedade moderna (BARROS, 1995).

A sociedade passou a aceitar quase por consenso a idéia de que alguém requeira cuidados médicos tão somente por estar grávida, ser recém-nascido, estar no período da menopausa ou na terceira idade (ILLICH, 1975). Como se, atingida qualquer dessas fases, a vida se converte numa sequiência de períodos a exigir, cada um deles, uma forma particular de consumo terapêutico (BARROS, 1995).

\section{A Criação das Agências Reguladoras da Ótica Liberal dos Anos 90}

Para se analisar o modelo regulatório da área da propaganda de medicamentos, sob responsabilidade da ANVISA, é necessário levar em conta a conjuntura vivida pelo Estado brasileiro quando do surgimento do conjunto de agências reguladoras, criadas na esteira da reforma do aparelho estatal, impactada diretamente pelo processo de globalização. Apesar das tentativas de demonstrar a "novidade" que esse processo traz, o caráter global do mercado, a desnacionalização da indústria, a internacionalização do processo produtivo, a interdependência das nações e mesmo a precarização e o rebaixamento dos limites dos contratos sociais já eram descritos por Marx em 1848, em O Manifesto Comunista.

Segundo Karl Marx e Friedrich Engels,

"a burguesia, através da exploração do mercado mundial, deu caráter cosmopolita para a produção e consumo em todos os países. Para grande desgosto 
dos reacionários, rebaixou a base nacional das indústrias até o rés do chão. As indústrias nacionais antigas foram destruídas ou seguem sendo destruídas dia após dia. Elas são desalojadas por novas indústrias, cuja introdução se torna questão de vida ou morte para todas as nações civilizadas; por indústrias que não mais trabalham com matéria-prima nacional, mas matéria-prima extraída de zonas remotas; cujos produtos são consumidos não só no próprio país, mas em todos os cantos do globo. Em lugar da antiga reclusão e autosuficiência local e nacional, temos conexões em todas as direções, uma interdependência universal das nações. E tanto em produção material como em produção intelectual" (MARX; ENGELS, 2003, p. 14-15).

Portanto, longe de ser um termo que retrata uma "realidade inovadora", a globalização dos anos 80 e 90 dá continuidade ao modelo histórico de acumulação internacional de poder e capital, cujas marcas indeléveis são "a hegemonia conquistada, em alguns países, pelos princípios neoliberais" e "a ofensiva contra os direitos sociais e o Estado de bem-estar, construídos desde a década de 1930 como a alternativa capitalista à redução das desigualdades" (SANTOS, 2000, p. 39).

Isso se torna política de Estado quando, em novembro de 1989 - como resultado de reunião que discutiu políticas econômicas e sociais para a América Latina, que passaram a ser defendidas por instituições como FMI, Banco Mundial e Banco Interamericano de Desenvolvimento - há um marco no chamado processo de globalização no continente latino-americano, consubstanciado no que se passa a chamar Consenso de Washington, cujas dez principais medidas são: 1) controle do déficit fiscal; 2) cortes nos gastos públicos; 3) reforma tributária; 4) administração das taxas de juros; 5) administração da taxa de câmbio; 6) abertura de mercado e ampla liberdade para importações; 7) liberdade para entrada e saída de investimentos externos; 8) privatização das empresas estatais; 9) desregulamentação da economia e das normas trabalhistas; 10) garantia do direito de propriedade industrial e intelectual.

O fortalecimento do mercado, em detrimento da presença do Estado como ente político, traduz um significativo fortalecimento da economia em relação à política. O Estado passa a abrir mão de parte de sua soberania, reduzindo seu poder e capacidade reguladora, passando a depender de novos pactos a serem negociados em torno de cada setor. Obviamente que esse imperativo para $o$ desenvolvimento, preconizado pelo Consenso, se traduz em discurso exclusivo para consumo externo e aplicação nos chamados países em desenvolvimento, 
já que em grande parte dos países centrais esse receituário simplesmente não é considerado ou é aplicado de forma a assegurar que os interesses locais e nacionais sejam preservados (COSTA, 1998).

Sob a ótica de que país confiável é aquele no qual o Estado não interfere no mercado, inicia-se nos anos 90, no Brasil, a Reforma Administrativa, cuja lógica determina que o Estado deve funcionar melhor e gastar menos, fazendo mais com menos recursos. As iniciativas essenciais, que se sobrepõem às demais, podem ser descritas como: flexibilização do regime administrativo de servidores e instituições públicas, maior proximidade de modelos de gestão das esferas pública e privada (tendo o privado como exemplo a ser seguido), relações contratuais não-permanentes em substituição ao modelo racional-legal weberiano, redução dos gastos públicos e do tamanho do aparato estatal (SANTOS, 2000).

No bojo dessa conjuntura, ressurge o debate sobre administração gerencial versus administração burocrática, que parte de um pressuposto: o patrimonialismo está superado, a administração burocrática está esgotada e a flexibilização do modelo racional-legal requer novos modelos de gestão. Segundo documentos elaborados pelo então Ministério da Administração Federal e Reforma do Estado (MARE), a concepção gerencial visa a

"fortalecer estrategicamente o Estado, [...] colocando-o no controle das políticas públicas, exercendo funções regulatórias onde o mercado não o faz e respondendo com agilidade às demandas sociais, buscando uma comunicação direta com sociedades cada vez mais complexas" (BRASIL, 1997, p. 7).

As propostas defendidas na ocasião pelo ministro Bresser Pereira, respaldadas pelo conjunto do governo Fernando Henrique Cardoso, partem do diagnóstico de que a Reforma do Estado envolve quatro questões essenciais: 1) delimitação do tamanho do Estado; 2) redefinição de seu papel regulador; 3) recuperação de sua capacidade financeira e administrativa de implementar decisões políticas tomadas pelo governo (apelidadas de "governança"); 4) aumento da capacidade política do governo de intermediar interesses, garantir legitimidade e governar (governabilidade). (SANTOS, 2000).

Entre as várias alternativas desenhadas no processo de reforma (agências executivas, organizações sociais etc.), as agências reguladoras recebem tratamento específico no âmbito da administração autárquica. De acordo com o modelo "bresseriano", elas são autarquias "especiais", voltadas 
a permitir o exercício de atividades regulatórias essenciais à proteção dos interesses dos usuários de serviços recém-privatizados e voltadas para a fiscalização de atividades econômicas. As agências reguladoras, ainda na concepção de Bresser Pereira, teriam sua gestão orientada pelos princípios da administração gerencial, com sua autonomia, portanto, revigorada (SANTOS, 2000).

Entretanto, essas agências - embora tenham obtido autonomia financeira e administrativa por força de lei - não conseguem ocupar um real papel regulatório, compatível com os argumentos e justificativas utilizados quando de seu surgimento. O ideário liberal da Reforma do Estado, que tem na flexibilização de contratos um de seus principais pilares, as impacta desde o nascedouro.

Entre os problemas enfrentados por elas estão:

1. inexistência de um quadro próprio de pessoal técnico qualificado, profissional, efetivo e protegido de interferências no exercício de suas atribuições. $\mathrm{Na}$ ausência deste quadro, as agências passam a se utilizar dos cargos em comissão; da livre nomeação e exoneração; e das contratações temporárias por excepcional interesse público, precarizando as relações de trabalho com impacto direto na sua performance;

2. inexistência de uma carreira para o quadro funcional;

3. demora na constituição das agências reguladoras, algumas delas só constituídas muito depois do processo de privatização dos setores que deveriam regular, gerando um vácuo na presença do Estado no setor;

4. importação de vícios e deficiências do antigo modelo regulatório, seja no plano institucional ou material, que tem impedido que elas cumpram efetivo papel regulador e fiscalizador frente às empresas;

5. inexistência de sistemas de informação que permitam ao Estado responder, com rapidez e eficácia, a problemas que tragam impacto à sociedade [ex.: "apagão", medicamentos falsificados, real cumprimento de metas pelas empresas etc.] (SANTOS, 2000).

Assim, o novo paradigma de atuação da esfera pública preconizado pela Reforma do Estado nos anos 90, pelo menos no que diz respeito às agências reguladoras e em particular à ANVISA, passados cinco anos de sua criação, perpetua velhos problemas do setor, como procuramos demonstrar a seguir. 


\section{A RDC 102 da ANVISA: mais uma tentativa frustrada de regular a propaganda de medicamentos}

Um dos principais parâmetros internacionais para se formatar um modelo regulatório para o setor da publicidade de medicamentos são os Critérios Éticos para a Promoção de Medicamentos, aprovados pela Organização Mundial de Saúde (OMS, 1985) em sua 39ª Assembléia Mundial, tendo como base a Conferência de Especialistas sobre Uso Racional de Medicamentos, realizada em Nairobi, em novembro de 1985. Esses critérios passaram a ser recomendados a todos os Estados-membros da OMS, assim como a fiscalização de seu cumprimento.

O Brasil já possuía legislações que regulavam o setor. Entre elas, se destacam a Lei ${ }^{\circ}$ 6.360/76, o Decreto n ${ }^{\circ} 79.094 / 77$ e a Lei no 8.078/90 (Código de Defesa do Consumidor). O texto regulatório mais recente, consubstanciado na publicação da Resolução de Diretoria Colegiada (RDC) da ANVISA, de ${ }^{\circ}$ $102 / 2000$ (de 30/11/2000, mas que só entrou em vigor em 30/05/2001, para que a indústria, as agências de publicidade e as empresas de comunicação tivessem tempo para se adequar a ela), nasceu da tentativa de pactuar uma regulação que refletisse, naquele momento, as ações possíveis numa área já regulada mas muito pouco fiscalizada.

Com um total de 25 artigos e algumas dezenas de alíneas e parágrafos, a RDC 102 é resultado de um processo de negociação entre os vários setores e interesses que giram em torno do mercado publicitário de medicamentos e do impacto que o uso irracional de medicamentos traz à saúde pública.

Entre uma série de exigências voltadas para o controle da publicidade de medicamentos, a RDC 102 da ANVISA impõe que toda propaganda conterá, ao final, obrigatoriamente, a advertência indicando que "Ao persistirem os sintomas, o médico deverá ser consultado".

\section{O Objetivo Deste Estudo}

O objetivo deste trabalho é analisar a forma de atuação das empresas de produção e distribuição de produtos farmacêuticos, assim como das agências de publicidade e empresas de comunicação. Por outro lado, a pesquisa - cujo foco é a propaganda de produtos comercializados sem exigência da prescrição - analisa o real impacto da Resolução no 102/2000 da ANVISA, editada com o 
objetivo de criar limites à propaganda de medicamentos com vistas a proteger e promover a saúde da população, assim como evitar agravos a ela. Este estudo avalia a capacidade do atual modelo regulatório de cumprir com esse objetivo.

\section{A Estratégia Metodológica}

Este trabalho se baseia na coleta de um total de cem peças publicitárias de medicamentos veiculadas em rádio, televisão, jornais, revistas, folhetos e outdoor - entre os meses de outubro de 2002 e julho de 2003. Posterior, portanto, à vigência da RDC 102 da ANVISA.

As peças publicitárias analisadas foram coletadas por equipes sediadas na Universidade Federal de Juiz de Fora (UFJF) e na Universidade Federal do Rio de Janeiro (UFRJ), que fazem parte do Projeto de Monitoração da Propaganda e Publicidade de Medicamentos, implementado pela Agência Nacional de Vigilância Sanitária (ANVISA). A coleta era feita de forma alternada em diferentes horários nas 24 horas do dia, sendo descartados os anúncios coletados anteriormente.

Foram selecionados os seguintes dados de cada uma das cem peças publicitárias: o nome fantasia do medicamento anunciado, o tipo de mídia em que a propaganda foi veiculada, o nome do laboratório farmacêutico produtor e a indicação sugerida na publicidade; o texto publicitário que sustenta o anúncio e finalmente os artigos da RDC 102 descumpridos pela referida publicidade.

\section{O Resultado da Análise}

A análise das cem peças publicitárias demonstra que o cumprimento das leis que regulamentam a propaganda de medicamentos no Brasil simplesmente não é observado, já que $100 \%$ dos anúncios coletados ferem um ou mais artigos da RDC 102. Ao se analisar os grupos terapêuticos mais anunciados no universo estudado, do total de 100 anúncios, 12 deles são de analgésicos; 12 de antigripais; 11 de tônicos / fortificantes / vitamínicos; 10 antiácidos; 9 são expectorantes / antitussígenos; 9 emagrecedores; 6 antiinflamatórios tópicos; 6 são para disfunções eréteis; 6 antitérmicos; 4 antisépticos; 3 descongestionantes; 3 antivaricosos / circulação venosa; 3 antiinflamatórios; 2 são vitaminas tópicas; 2 antiespamódicos, 2 antiescabiose / piolhos; 2 laxativos / purgativos e foi registrado um anúncio para cada um dos 
seguintes grupos: antimicrobiano, antimicótico, hepatoprotetor, anti-helmíntico; antidiarréico, anti-reumático; calmante, antialopecia / calvície; terapia de reposição hormonal e um cuja classificação não se pôde definir, devido às múltiplas indicações referenciadas na publicidade.

Entre os laboratórios que mais anunciam, o Dorsay Monange (DM) Indústria Farmacêutica está presente em 21 dos 100 anúncios; 15 são de laboratórios não informados na propaganda; 5 da Belém Jardim Fitoterápicos; 4 da EMS Indústria Farmacêutica; 4 da Smithkline Beecham do Brasil; 4 do Laboratório Wyeth-Whitehall Ltda.; 3 da Procter e Gamble do Brasil; 3 da Schering-Plough; 3 do Laboratório Catarinense; 3 do Laboratório Aventis Pharma; 3 da Pfizer do Brasil; 3 da Boehringher do Brasil; 2 da Roche do Brasil; 2 da Luper Farmacêutica; 2 da Indústria Farmacêutica Milian; 2 da Staford Miller Indústria Ltda.; 2 da Bristol Myers-Squibb; 2 do Zurita Laboratório Farmacêutico Ltda.; 2 da Janssen-Cilag Farmacêutica Ltda.; e uma inserção publicitária das seguintes indústrias: Laboratório Bauer, Laboratório Vitalab Ltda., Merck S/A, Laboratório Klinger do Brasil, Newlab Indústria Farmacêutica Ltda., Altana Pharma Group, Sankio Pharma Brasil, Laboratório Hepacholan do Brasil, Eurofarma, Indústria Farmacêutica Farmabraz Beta Atalaia, Asta Médica Ltda., Laboratório Farmacêutico Vitamed Ltda., União Química Farmacêutica Nacional Ltda., Stem Pharmaceutical e Zest Farmacêutica.

Entre os artigos da RDC 102 mais descumpridos nas cem peças de propaganda analisadas estão:

1. Art. $3^{\circ}$, Alínea I (que obriga que conste "de forma clara e precisa a contra-indicação principal" do medicamento anunciado), que é descumprido em 94 dos 100 anúncios analisados;

2. Art. $10^{\circ}$, Parágrafo IV (que veda que a publicidade venha a "sugerir ou estimular diagnósticos aconselhando um tratamento correspondente"), descumprido 52 vezes.

3. Art. $12^{\circ}$, Alínea A (que determina que "a propaganda, publicidade e promoção de medicamento de venda sem exigência de prescrição deverão incluir, além das informações constantes no inciso I do artigo $3^{\circ}$ desta regulamentação: a) o nome comercial do medicamento; o número de registro na ANVISA e o nome dos princípios ativos segundo a DCB e na sua falta a DCI"), descumprido 50 vezes; 
4. Art. $10^{\circ}$, Parágrafo 1 (que veda "na propaganda, publicidade e promoção de medicamentos de venda sem exigência de prescrição" a ação de "estimular e/ou induzir o uso indiscriminado de medicamentos e/ou emprego de dosagens e indicações que não constem no registro do medicamento junto à ANVISA"), descumprido 33 vezes;

5. Art. $10^{\circ}$, Parágrafo $X$ (que proíbe o uso "de linguagem direta ou indireta relacionando o uso de medicamento ao desempenho físico, intelectual, emocional, sexual ou a beleza de uma pessoa, exceto quando forem propriedades aprovadas pela Agência Nacional de Vigilância Sanitária”), descumprido 26 vezes;

6. Art. $4^{\circ}$, Parágrafo X (que veda a ação de "sugerir ausência de efeitos colaterais ou adversos ou utilizar expressões tais como: 'inócuo', 'seguro' ou 'produto natural', exceto nos casos registrados na ANVISA"), descumprido 20 vezes;

7. Art. $12^{\circ}$, Alínea B (que determina que "a propaganda, publicidade e promoção de medicamento de venda sem exigência de prescrição deverão incluir, além das informações constantes no inciso I do artigo $3^{\circ}$ desta regulamentação, a advertência 'Ao persistirem os sintomas, o médico deverá ser consultado')", descumprido 19 vezes.

8. Artigo $4^{\circ}$, Parágrafo VII (que proíbe a sugestão de "diminuição de risco, em qualquer grau, salvo nos casos em que tal diminuição de risco conste explicitamente das indicações ou propriedades aprovadas no ato de registro junto à Agência Nacional de Vigilância Sanitária e, mesmo nesses casos, apenas em publicações dirigidas aos profissionais de saúde"), descumprido 18 vezes;

9. Artigo $4^{\circ}$, Parágrafo I (que veda que se anuncie "medicamentos não registrados pela Agência Nacional de Vigilância Sanitária nos casos exigidos por lei"), descumprido 17 vezes;

10. Artigo $10^{\circ}$, Parágrafo VIII (que veda "afirmar e/ou sugerir ter um medicamento efeito superior a outro, usando expressões tais como: 'mais eficaz', 'menos tóxico', ser a única alternativa possível dentro da categoria ou ainda utilizar expressões, como: 'o produto', 'o de maior escolha', 'o único', 'o mais freqüentemente recomendado', 'o melhor'. As expressões só poderão ser utilizadas se comprovadas por evidências científicas, e previamente aprovadas pela ANVISA"), descumprido 17 vezes. 
A comparação entre o conteúdo das cem peças publicitárias e as determinações da RDC 102 da ANVISA demonstra existir uma média de 4,13 irregularidades por anúncio, com alguns anúncios chegando a conter até dez tipos de infrações à legislação. Para se assegurar a uniformidade da análise, o conteúdo dos anúncios e o da RDC 102 foram comparados pelo mesmo pesquisador.

Ao se analisar os termos mais utilizados no universo de cem peças coletadas, as palavras emagrecer e/ou emagrecedor aparecem 40 vezes; dor, 28 vezes; gripe, 21 vezes; alivia e/ou alívio imediato, 19 vezes; saúde, 17 vezes; rápido e/ou rapidinho, 15 vezes; tosse, 15 vezes; problema, 15 vezes; azia, 15 vezes; melhor e/ou melhorar, 14 vezes; energia, 14 vezes; natural, 12 vezes; vitamina $C, 11$ vezes; passa e/ou passar, 11 vezes; bom, 8 vezes; sintomas, 8 vezes; legal, 8 vezes; eficiente, e/ou eficaz e/ou eficácia, 8 vezes; saudável, 7 vezes e má digestão, 7 vezes.

A análise do conteúdo das mensagens de texto e das imagens da grande maioria delas mostra uma tendência a se superestimar as qualidades dos produtos anunciados e omitir seus aspectos negativos. Os anúncios enaltecem as características favoráveis do medicamento, muitas vezes atribuindo-lhes uma onipotência duvidosa e uma posição central na terapêutica, sem apresentar uma sustentação com base em dados científicos.

Por outro lado, a ausência de contra-indicações (o artigo mais ferido pelas publicidades analisadas) reflete o quanto as informações sobre riscos, efeitos adversos, advertências e precauções são negadas ao consumidor. Não é exagero concluir que, do ponto de vista publicitário, veicular informações sobre riscos e possíveis agravos é visto, pelo marketing medicamentoso, como uma contrapropaganda do produto.

Os argumentos mais utilizados na propaganda analisada ressaltam, principalmente, a eficácia, a segurança, o bem-estar, a comodidade na administração, a rapidez da ação do medicamento, além do bom humor, da energia, do prazer e da felicidade que eles trazem, minimizando ao máximo, ou simplesmente excluindo, qualquer referência a riscos, possíveis interações medicamentosas ou contra-indicações. Estas, quando aparecem, em geral são exibidas em letras minúsculas, que surgem muito rapidamente, na maioria das vezes frisando apenas que aquele determinado medicamento "é contra-indicado para as pessoas com hipersensibilidade aos componentes da fórmula", evitandose determinar quais os grupos populacionais que não devem tomar o medicamento, como idosos, crianças, diabéticos, hipertensos e outros. 
Em boa parte dos casos, a propaganda voltada para o grande público se utiliza de apresentadores de programas de rádio e televisão, artistas e atletas famosos, como forma de induzir o consumo de determinado medicamento, seja pelo padrão de beleza, pela confiabilidade ou pelo desempenho físico demonstrado por eles.

\section{Conclusão}

Seja em relação à magnitude das irregularidades (100\% do universo analisado indica pelo menos um tipo de infração), seja em relação à pouca eficácia das ações regulatórias (poucos são os anúncios retirados do ar e ínfimos os valores das multas aplicadas), a realidade do setor mostra que não é apenas um maior rigor na esfera da fiscalização onde reside o problema. A questão é mais ampla e se localiza na própria forma como se estrutura o modelo regulatório vigente.

Analisando-se o tema em questão e a forma como se dá a regulação hoje existente na área da propaganda de medicamentos dirigida para o grande público no Brasil, é possível listar pelo menos três características desse modelo regulatório constatadas durante a coleta de dados para esta pesquisa:

$1^{\text {a) }}$ a atual regulação é feita a posteriori, isto é, a agência atua após a veiculação da peça publicitária. Entre a colocação do anúncio no mercado (e a identificação da irregularidade) e a tomada de medidas no âmbito do modelo regulatório (quando este é o caso), transcorre um período de tempo de mais de um mês, o que faz com que a ação reguladora se realize quando "o mal já está feito";

$2^{\mathrm{a}}$ ) as multas efetivamente arrecadadas pela ANVISA, quando ocorrem as irregularidades, têm valor irrisório frente ao total de gastos com propaganda realizados no setor. Para se ter uma idéia, em um ano e meio de regulação a ANVISA recolheu em multas valores equivalentes a apenas dois anúncios no horário nobre da TV. Por outro lado, não há nada, no atual modelo regulatório, que impeça que os valores relativos às multas sejam transferidos pela indústria para o preço dos medicamentos (o que ela já faz com o conjunto dos gastos com publicidade de seus produtos), sendo pagos pelo próprio consumidor;

$3^{\text {a) }}$ ao estampar a frase "AO PERSISTIREM OS SINTOMAS, O MÉDICO DEVERÁ SER CONSULTADO” ao final de cada propaganda, a 
pretendida regulação na verdade estimula o consumo irracional de medicamentos, quando caberia ao Estado cumprir justamente a tarefa oposta, de acordo com o preconizado pela Política Nacional de Medicamentos (Portaria do Ministério da Saúde no 3.916, de 30/10/1998), educando a população no sentido de "ANTES DE CONSUMIR QUALQUER MEDICAMENTO, CONSULTAR UM MÉDICO”. Na prática, a mensagem final da atual regulação deseduca e presta inestimável papel à indústria e ao comércio, e não à sociedade a quem deveria proteger. $\mathrm{O}$ que o atual modelo regulatório transmite à população pode ser traduzido pela seguinte mensagem: "PRIMEIRO TENTE ENCONTRAR O MEDICAMENTO QUE LHE TRAGA A CURA, COMPRANDO O PRODUTO QUE JULGAR MAIS CONVENIENTE. CASO NÃO OBTENHA SUCESSO, PROCURE UM MÉDICO PARA AJUDÁ-LO”.

Mesmo que a ANVISA multiplique várias vezes sua atuação, as propagandas irregulares continuariam a ser reprimidas a posteriori, as multas continuariam a ser de um valor irrisório, seus custos continuariam sendo repassados aos preços dos medicamentos (e pagos pelo consumidor) e a advertência colocada a cada final de propaganda permaneceria estimulando o uso irracional de medicamentos. Pode-se afirmar que o atual modelo regulatório da propaganda de medicamentos, da ótica do que significa um "risco sanitário", apresenta substantiva fragilidade.

Esta pesquisa demonstra a urgência de um esforço regulatório mais rígido e abrangente, que contribua para a diminuição do uso incorreto de medicamentos, reduzindo os casos de reações adversas e os índices de intoxicação humana provocados por produtos farmacêuticos, elevando o nível de informação e consciência da população sobre a questão e evitando o contínuo crescimento de agravos à saúde.

A propaganda de medicamentos realizada hoje no Brasil entra em clara contradição com a atual Política Nacional de Medicamentos (Portaria do Ministério da Saúde $\mathrm{n}^{\circ} 3.916$, de 30/10/1998), segundo a qual o uso de produtos farmacêuticos deve se dar de forma racional, ética e correta, preconizando explicitamente um maior "controle da propaganda dos medicamentos de venda livre". Sendo assim, faz-se necessária uma revisão profunda dos atuais mecanismos regulatórios do setor, no caminho de superação das enormes fragilidades apontadas neste estudo, que demonstra que a propaganda de medicamentos realizada no universo analisado tenta "seduzir" o consumidor psicologicamente, utilizando mensagens que se situam no campo da 
vulnerabilidade humana e naqueles de maior importância na sua vida - incluindo aí o papel social que cada indivíduo desempenha no seu meio.

Um enfrentamento da questão não pode deixar de considerar o aspecto cultural que a permeia, que através do tempo se arraigou entre prescritores, pacientes e no conjunto da sociedade, segundo o qual o medicamento é fator essencial em qualquer terapêutica. Por isso, uma reforma no sistema de ensino e de assistência - que acople uma visão crítica da prática médica e da educação sanitária da população - se faz necessária, com vistas a alterar os atuais padrões de comportamento e formar uma consciência que estimule novos hábitos relativos ao consumo de produtos feitos para promover a saúde, prevenir e curar doenças, mas que trazem em si o componente da ineficácia terapêutica e, pior, das reações adversas.

Outro fator importante a ser suprimido da publicidade é o estímulo a maus hábitos alimentares que alguns produtos trazem em suas mensagens. Em algumas delas, ingerir comidas gordurosas e em excesso não traz problema, desde que acompanhado de determinado sal de fruta ou droga contra azia e má digestão. Beber em demasia também não precisa ser evitado, bastando tomar "um Engovâ antes e outro depois".

No terreno específico da propaganda, o conflito de interesses entre a realidade demonstrada na pesquisa e o uso racional do medicamento pode ser enfrentado através de ações de caráter público. Tais ações podem articular os interesses dos segmentos industriais, dos profissionais de saúde responsáveis pela prescrição (médicos e odontólogos) e dispensação (farmacêuticos), além de representantes dos órgãos de defesa do consumidor e gestores do SUS, no sentido de construir um novo modelo regulatório que assegure a disseminação de informações cientificamente embasadas e isentas. Essas ações se materializariam em formulários terapêuticos nacionais, boletins independentes e demais instrumentos de educação em saúde. Resumindo, a implantação de políticas globais que utilizem os instrumentos de informação e comunicação voltados para o uso correto e racional de medicamentos é uma diretriz fundamental a ser assumida pela Política Nacional de Saúde.

Por outro lado, faz-se necessário que a ANVISA assuma com tenacidade seu papel de vigilância, fiscalização e instrumento de punição das irregularidades. Hoje a agência, diante dos dados alarmantes da pesquisa encomendada por ela própria, privilegia seu papel de implementadora "de políticas de educação e conscientização da população sobre os perigos da 
automedicação" e de "mudança no perfil dos profissionais envolvidos no projeto dentro da universidade", abrindo mão de exercer seu papel de polícia sanitária.

Rozenfeld (2003) lista algumas diretrizes essenciais a serem assumidas pela ANVISA ou pelo órgão que eventualmente vier a assumir um verdadeiro papel regulador na área:

“1) concentrar-se nas atividades-fins, no chamado exercício de polícia sanitária, dirigida aos campos de maior risco para a saúde. Agir segundo parâmetros epidemiológicos, isto é, selecionar grupos vulneráveis e protegê-los em caráter prioritário, sobretudo idosos, doentes crônicos, crianças e gestantes;

2) trabalhar com a atual legislação sanitária que, embora possa ser detalhada, é mais do que suficiente para sanear o mercado;

3) enfrentar, com coragem, os fabricantes de produtos e prestadores de serviço que afetam a saúde. Verificar as inconformidades, as fraudes, os erros e as inadequações, punindo severamente os infratores;

4) articular a formação de recursos humanos às diretrizes da política de vigilância sanitária. O treinamento e a capacitação dos profissionais devem subordinar-se às metas de proteção à saúde dos usuários;

5) envolver a sociedade e os órgãos de defesa do consumidor na educação para a saúde.

6) evitar ações dispersas. Os problemas estão diagnosticados há décadas;

7) proceder a revisões técnicas de produtos farmacêuticos, por classes terapêuticas, segundo o risco, com ações saneadoras significativas. Cancelamento do registro de produtos ineficazes ou danosos, seguido de um rigoroso "cumpra-se";

8) evitar pulverização dos recursos em atividades-meio;

9) inspecionar e fiscalizar regularmente os laboratórios fabricantes e demais agentes econômicos, divulgando os resultados;

10) estabelecer integração com os níveis estadual e municipal, para além das relações de co-patrocínio". 
A principal conclusão deste estudo indica a necessidade de se estabelecer novos, efetivos e mais rigorosos mecanismos de controle público da propaganda de medicamentos no Brasil, assim como o acompanhamento de sua implementação e a avaliação de seu impacto na saúde da população. Um tratamento prioritário a essas questões, no conjunto da sociedade e no interior do SUS, pode superar a lógica atual, na qual os interesses econômicos de expansão de mercado e acumulação de capital se sobrepõem aos interesses da cidadania e da saúde pública.

\section{Agradecimentos}

É indispensável o agradecimento à Direção da Agência Nacional de Vigilância Sanitária (ANVISA) e aos grupos responsáveis (na Universidade Federal de Juiz de Fora e na Universidade Federal do Rio de Janeiro), pela cessão das peças publicitárias coletadas no âmbito do Projeto de Monitoração da Propaganda de Medicamentos.

\section{Referências}

ASSOCIAÇÃO BRASILEIRA DE PÓS-GRADUAÇÃO EM SAÚDE COLETIVA. Pelo direito universal à saúde: Contribuição da Abrasco aos debates da $8^{a}$ Conferência Nacional de Saúde. Rio de Janeiro: ABRASCO, 1985, p. 25.

ANVISA. Resolução de Diretoria Colegiada (RDC) 102/2000. Disponível em http://www.ANVISA.gov. br/legis/resol/2000/102. Acesso em: 01 jun de 2003.

. Projeto de monitoração de propaganda e publicidade de medicamentos. Agência Nacional de Vigilância Sanitária, Brasília: 2002.

BARDIN, L. Análise de conteúdo. Lisboa: Edições 70, 1995.

BARROS, J. A. C. Propaganda de medicamentos: atentado à saúde? São Paulo: Hucitec, 1995.

BERMUDEZ, J. Indústria farmacêutica, estado e sociedade. São Paulo: Hucitec, 1995. 
BERMUDEZ, J.; EPSZTEJN, R.; OLVEIRA, M.; HASENCLEVER, L. $O$ acordo TRIPS e a proteção patentária no Brasil. Rio de Janeiro: ENSP/ Fiocruz, 2000.

BOBBIO, N.; MATEUCCI, N.; GIANFRANCO, P. Dicionário de política. 5 ed. Brasília: Editora Universidade de Brasília; São Paulo: Imprensa Oficial do Estado, 2000.

BOYER, R. A Teoria da regulação: uma análise crítica. São Paulo: Nobel, 1990.

BRASIL. LEI n ${ }^{\circ} 6.360$ de 23 de setembro de 1976. Dispõe sobre vigilância sanitária a que ficam sujeitos os medicamentos, as drogas, os insumos farmacêuticos e correlatos, cosméticos, saneantes e outros produtos. Brasília, DF, 24 set. 1976. Disponível em: www.cff.org.br/legis/leis/lei_6360_76.html. Acesso em: 10 julho 2003.

BRASIL. Ministério da Administração Federal e Reforma do Estado. A nova política de recursos humanos. Cadernos do MARE da Reforma do Estado, Brasília, n 11, 1997.

BRASIL. Congresso. Senado. Relatório Final da CPI de Medicamentos. Brasília: Senado Federal, 2000.

BRASIL. Congresso. Câmara. Voto em Separado ao Relatório Final da CPI de Medicamentos. Brasília, 2000.

BRASIL. Decreto № 79.094, de 5 de janeiro de 1977. Regulamenta a Lei ${ }^{\circ}$ 6.360 de 23 set. 1976, que submete a sistema de vigilância sanitária os medicamentos, insumos farmacêuticos, drogas, correlatos, cosméticos, produtos de higiene, saneamento e outros. Disponível em www.cff.org.br/legis/decretos/ decreto 79094_77.html. Acesso em: 10 jul. 2003.

BRASIL. Ministério da Saúde. Sistema Nacional de Informações TóxicoFarmacológicas: estatística anual de casos de intoxicação e envenenamento. Rio de Janeiro: Fiocruz, CICT. 1995 - 2002.

BRASIL. Ministério da Saúde. Portaria 3.916, de 30 de outubro de 1998. Estabelece a Política Nacional de Medicamentos. Brasília: Ministério da Saúde. Disponível em http://dtr2001.saude.gov.br/doc/Portarias/3916\%20.rtf. Acesso em: 10 de julho de 2003. 
BRASIL. Ministério da Saúde. Relatório Final da $11^{a}$ Conferência Nacional de Saúde. Brasília, 2001. Disponível em http://conselho.saude.gov.br/ 11conferencia/11c relatorio.htm. Acesso em: 10 jun de 2003.

BRASIL. Ministério da Saúde. Secretaria de Gestão de Investimentos em Saúde. Projeto de Modernização da Produção Pública de Medicamentos. Brasília: Ministério da Saúde, 2000.

COSTA, E. A. Vigilância Sanitária: proteção e defesa da saúde. São Paulo: Hucitec, 1999.

COSTA. V.M.F. O novo enfoque do Banco Mundial sobre o estado. Lua Nova - Revista de Cultura e Política, n. 44, 1998.

DIAS, H. P. A responsabilidade pela saúde: aspectos jurídicos. Rio de Janeiro: FIOCRUZ, 1995.

EINARSON, T. R. Drug-related hospital admission. Ann Pharmacoter, v. 27, n. 7, p. 832-840, 1993.

FEBRAFARMA. Departamento de Economia da Federação Brasileira da Indústria Farmacêutica. Disponível em: www.febrafarma.org.br. Acesso em 24/10/2003.

HARVEY, D. Condição pós-moderna: uma pesquisa sobre as origens da mudança cultural. São Paulo: Edições Loyola, 1989.

HEINECK, I; GALLINA, S.M; SILVA, T; PIZZOL, F.; SCHENKEL, E. Análise da publicidade de medicamentos veiculada em emissoras de rádio do Rio Grande do Sul, Brasil. Cadernos de Saúde Pública, v. 14, n. 1, p. 193 198. 1998.

HERXHEIMER, A; COLLIER, J. Promotion by the british pharmaceutical industry, 1983-8: a critical analysis of self regulation. Londres: BMJ. 1990.

HURREL, A. O ressurgirmento do regionalismo na política mundial. Contexto Internacional, Brasília, v. 17, n. 1, jan-jun, 1995.

ILLICH, I. A expropriação da saúde: nêmesis da medicina. Rio de Janeiro: Nova Fronteira, 1975.

LAZAROU, J.; POMERANZ, B.H; COREY, P.N. Incidence os adverse drug reactions in hispitalized patients: a meta-analysis of prospective studies. Journal of American Medical Association, Chicago, v.279, n.15, p. 1200-1205. 1998 
LEFÈVRE, F. O medicamento como mercadoria simbólica. São Paulo: Cortez, 1991.

MANAGEMENT Sciences for Health - MSH. Manging Drug Supply. 2 ed. Connecticut: Kumarian Press, 1997.

MARX, K. O capital: crítica da economia política. 2 ed. Rio de Janeiro: Civilização Brasileira, 2002. Livro I, v.1 (O processo de produção do capital).

MARX, K. \& ENGELS, F. O manifesto comunista. Rio de Janeiro: Paz e Terra, 2003.

EXAME. Melhores e Maiores. São Paulo: Editora Abril, jun. 1999.

MAXIMIANO, A. A.; CARDOSO, L. A. Propaganda de medicamentos no Brasil: análise das manifestações públicas sobre regulamentação. Brasília, 2000. 115 f. Monografia (Especialização em Saúde Coletiva) - Faculdade de Ciências da Saúde, Universidade de Brasília.

NASCIMENTO, M.C. A centralidade do medicamento na terapêutica contemporânea. 138 f .Tese (Doutorado em Saúde Coletiva) - Instituto de Medicina Social, Universidade do Estado do Rio de Janeiro, 2002.

NAVARRO MOLL, M.C. Uso racional de plantas medicinales. Pharm Care Esp: v.2 p. 9 - 19, 2000. Disponível em http://www.pharmaceutical-care.es/ esp/2000/n1/pdf/revisiones2.pdf. Acesso em: 15 julho 2003.

OLIVEIRA, G. O. A indústria farmacêutica e o controle internacional de medicamentos. Brasília: Gráfica do Senado, 1998.

ORGANIZAÇÃO MUNDIAL DE SAÚDE. Critérios éticos para la promoción de medicamentos. Genebra: Organização Mundial da Saúde, 1988. Disponível em www.who.int/medicines/espanol/criterios/criterioseticos.pdf . Acesso em: 26 jun. 2003.

OSÓRIO-DE-CASTRO, C. Estudos de Utilização de Medicamentos: noções básicas. Rio de Janeiro: Fiocruz, 2000.

PEPE, V.L.E.; VERAS, C. M. T. A prescrição médica. Rio de Janeiro: UERJ/ IMS, 1995 (Série Estudos em Saúde Coletiva, 111).

RIO DE JANEIRO (Estado). Secretaria Estadual de Saúde. Cuidados no uso de Plantas Medicinais. Rio de Janeiro, 2003. Disponível em: www.saude.rj.gov.br/proplan. Acesso em: 15/10/2003. 
ROZENFELD, S. Fundamentos da vigilância sanitária. Rio de Janeiro: Editora Fiocruz, 2000.

ROZENFELD, S. Reações adversas aos medicamentos na terceira idade: as quedas em mulheres com iatrogenia farmacoterapêutica, 1987. Tese (Doutorado em Saúde Coletiva) - Instituto de Medicina Social, Universidade do Estado do Rio de Janeiro, Rio de Janeiro.

ROZENFELD, S. Uso de medicamentos no Brasil. In: LAPORTE, J.R.; TOGNONI (Orgs). Epidemiologia do medicamento: princípios gerais. 1 ed.. Rio de Janeiro: Hucitec, 1989.

ROZENFELD, S. Vigilância: as mudanças necessárias. Revista Riopharma, Rio de Janeiro, Ano XII, n ${ }^{\circ}$ 44, mar./abr. de 2003,

SACRAMENTO, H. Alerta aos amantes da fitoterapia. Disponível em www.escelsanet. com.br/sitesaude/artigos cadastrados. Acesso em: 12 julho de 2003.

SACRAMENTO, H. Dez dicas para usar melhor as plantas medicinais. Disponível em www.escelsanet.com.br/ sitesaude/artigos cadastrados. Acesso em: 12 julho de. 2003.

SANTOS, L. A. agencificação, publicização, contratualização e controle social: possibilidades no âmbito da reforma do aparelho do estado. Brasília: DIAP, 2000.

SAYD, J. D. Mediar, medicar, remediar: aspectos da terapêutica na medicina ocidental. Rio de Janeiro: EdUERJ, 1998.

SCHENKEL, E. P. Cuidado com os Medicamentos. Porto Alegre: Editora da Universidade Federal do Rio Grande do Sul .2 ed. rev. e ampl., 1991.

SOBRAVIME Acción Internacional para la Salud - América Latina y Caribe. O que é uso racional de medicamentos. São Paulo: Sobravime, 2001.

TEMPORÃO, J. G. A propaganda de medicamentos e o mito da saúde. Rio de Janeiro: Graal, 1986. 
“Ao Persistirem os Sintomas, o Médico Deverá Ser Consultado"...

\section{NOTAS}

* Graduado em Jornalismo pela Universidade Federal Fluminense, tecnologista no Departamento de Ciências Sociais da Ensp/Fiocruz, mestre e doutorando em Saúde Coletiva pelo Instituto de Medicina Social da UERJ. Endereço eletrônico: alvaron@ensp.fiocruz.br.

** Médica, doutora em Saúde Coletiva e professora adjunta no Departamento de Planejamento e Administração em Saúde do Instituto de Medicina Social da UERJ. Endereço eletrônico: janes@ims.uerj.br.

${ }^{1}$ Denominados como "BO’s" - bons para otário. 


\section{ABSTRACT}

\section{"If your symptoms fail to improve, consult a doctor." Is this regulation?}

The triad formed by the pharmaceutical industry, advertising agencies, and communications companies has deployed an intense marketing strategy to increase drug consumption by the population. This reality raises a challenge: in the use of medicines, where does the treatment demand for controlling diseases end and the market pressure to encourage consumption begin? In addition, exploitation of medicines' symbolic value by the mainstream media becomes a powerful tool to induce habits and increase drug consumption. Medicines have been the leading cause of human poisoning in Brazil since 1995 (if one includes suicide attempts, they become the second most common cause, according to Annual Statistics on Cases of Human Intoxication and Poisoning, Sinitox, 1995-2002). All medicines entail potential risk, and the adverse reactions multiply with incorrect and indiscriminate use. The elderly, children, and individuals with chronic diseases form a huge contingent exposed to drug advertising, with no warning as to the use of substances that can be harmful to these groups. In November 2000 the National Health Surveillance Agency (ANVISA) published Ruling 102, attempting to place limits on the industry. The current study analyzes 100 drug advertisements published from October 2002 to July 2003, compares their messages with the provisions of the new legislation, and concludes that they all violate one or more articles of the Ruling. Beyond greater surveillance, this study discusses the regulatory model itself, which has failed to reach its own self-defined objectives.

Key words: Medicines; health surveillance; advertising ethics; regulation; media. 